Eixo Temático: Processos de Ensino-Aprendizagem

\title{
ET-06-007 \\ RELATO DE EXPERIÊNCIA SOBRE O EXERCÍCIO DA AULA PRÁTICA DURANTE O ESTÁGIO SUPERVISIONADO I EM UMA TURMA DO COLÉGIO MUNIPICIPAL DE ALAGOINHAS, BAHIA, BRASIL
}

\author{
Maise Souza Vieira1 ${ }^{1}$ Magnólia Silva Queiroz²
}

${ }^{1}$ Estudante de Licenciatura em Ciências Biológicas pela Universidade do Estado da Bahia, Campus II.

2Professora assistente, do Departamento de Ciência Exatas e da Terra-DECT II, da Universidade do Estado da Bahia, Campus II.

http://dx.doi.org/10.21472/congrebio2016.et-06-007

\section{RESUMO}

É imprescindível a necessidade dos estagiários vivenciarem a prática docente em escolas de educação básica, bem como saber utilizar novas ferramentas para introduzir um ensino de qualidade na sala de aula, sendo uma dessas ferramentas a experimentação. Nesse contexto, o presente relato objetivou retratar sobre uma aula prática ocorrida em uma turma de $6^{\circ}$ ano do Colégio Municipal de Alagoinhas, para observação das alterações físicas e químicas envolvidas no processo de combustão da vela como um dos momentos importantes do estágio. Pôde-se notar a partir dessa experiência docente a importância do aspecto da prática para tornar as aulas mais participativas e estimulantes.

Palavras-chave: Relato de experiência; Aula prática; Estágio.

\section{INTRODUÇÃO}

Tendo em vista a situação do mundo atual e a forma como os jovens estão inseridos no mesmo, a passagem pelo componente de estágio configura, sobretudo, um momento de grande importância para o efetivo exercício da profissão docente como uma manobra para melhorar o processo de ensino-aprendizagem para a nova geração de professores e suas relações com os alunos no ambiente escolar.

Pensando nesta perspectiva, Souza e Gonçalves (2012) afirmam que a prática supervisionada no ensino de ciências faz-se necessária para a tomada de consciência dos futuros professores acerca das teorias estudadas, mas em hipótese alguma, estas teorias relacionadas ao saber; são suficientes para o pleno exercício da docência. Sendo assim, é imprescindível a necessidade dos estagiários vivenciarem a prática docente em escolas de educação básica, bem como saber utilizar novas ferramentas para introduzir um ensino de qualidade na sala de aula, sendo uma dessas ferramentas a experimentação.

Segundo Rosito (2008), o ensino de Ciências tem considerado para uma significativa aprendizagem científica, a prática de atividades experimentais, tanto na sala de aula como no laboratório, pois atividades práticas propiciam uma interação maior entre professores e alunos, proporcionando também a oportunidade de um planejamento conjunto e a elaboração de estratégias de ensino, induzindo assim os alunos a uma melhor compreensão dos processos da Ciência.

No Brasil, as atividades práticas são consideradas uma forma de favorecer a consecução dos objetivos propostos pelos Parâmetros Curriculares Nacionais (PCN) para o ensino de Ciências. Assim, é fundamental que o ensino de Ciências se volte ao desenvolvimento de competências que permitem a investigação, a comunicação e o debate de fatos e ideias, 
possibilitados pela observação, experimentação, demonstração, comparação, estabelecimento de relações entre fatos ou fenômenos (BRASIL, 1998).

Neste sentido, Villani e Freitas (1998) revelam que em estudo realizado de ensino através da prática, é possível estabelecer três categorias progressivas de sucesso escolar: envolvimento intelectual, emocional, e o confronto e posicionamento do educando em relação ao saber científico.

Desse modo, neste trabalhoestá descrito o relato de experiênciacom o objetivo de retratar um momento de experimentação com uma turma do $6^{\circ}$ ano do Ensino Fundamental II, de forma a exercitar as novas propostas de ensino de Ciênciase, assim, promover uma troca de saberes entre o conhecimento escolar e os saberes construídos pelos alunos mediados pelo conhecimento empírico.

\section{METODOLOGIA}

O estágio de regência foi realizado no Colégio Municipal de Alagoinhas durante o componente curricularsemestral obrigatório Estágio Supervisionado I, do Curso de Licenciatura em Ciências Biológicas, da Universidade do Estado da Bahia, Campus II, Alagoinhas-BA.

Durante um longo período percebeu-se que poucos alunos estavam frequentando regularmente as aulas de Ciências, desse modo, algo diferenciado teria que ser aplicado a fim de conquistar a atenção de todos e de maneira que o assunto estivesse claro e objetivo para os estudantes. Pensando nesta perspectiva, foi elaborada uma aula prática sobre a combustão da vela para desenvolver em sala de aula. Faz-se necessário enfatizar que o conteúdo da unidade abordado era: os "gases que constituem a atmosfera", o que é era significativamente desafiador, posto que tal conteúdo muitas vezes resulte em pouca compreensão já que é consideravelmente abstrato.

Assim, o primeiro momento foi iniciado apresentando aos estudantesalguns questionamentos como: "o que aconteceria se fosse possível extrair todo o oxigênio na atmosfera?"; "se pudéssemos entrar em uma cápsula de vidro por um período longo de tempo e contendo oxigênio, sobreviveríamos?”; “o que é crucial para que uma chama possa se manter acesa”? Tais perguntas foram elaboradas com o intuito de despertar a curiosidade e propositalmente, promover dúvidas e inquietações.

No segundo momento, o experimento foi montado em sala de aula com materiais do cotidiano:experimento no qual uma vela acesa, presa à superfície interna de um prato é encapsulada por um copo; e o experimento teste em que a vela não foi encapsulada por um copo. Nesse experimento, alguns segundos após a chama da vela ser coberta, ela se apaga, enquanto que, no experimento teste, a vela se mantém acesa. É um experimentofácil, que exige poucos recursos, e ao mesmo tempo completo o suficiente para compreender de modo visível a importância da presença dos gases na atmosfera, neste caso o oxigênio.

No terceiro momento, os alunos propuseram uma explicação em forma de texto para o experimento quanto às alterações físicas e químicas envolvidas no processo de combustão da vela, assim comojustificaram o motivo pelo qual a vela que estava sem o copo mantinha-se constantemente acesa.

\section{RESULTADOS E DISCUSSÃO}

A partir da análise dos textos, observou-se que os alunos levantaram suas hipóteses acerca do fenômeno através de seus conhecimentos empíricos, sendo importante reproduzir fragmentos de algumas das descrições: a vela encapsulada se apaga em decorrência da "falta de ar no copo", "pelo oxigênio no local”, "pela falta de oxigênio". Faz-se importante ressaltar que todas as hipóteses levantadas pelosalunos (embora que algumas estivessem equivocadas) puderam ser aproveitadas pela estagiária através de inferências, de maneira que tais observações fossem melhoradas, aprimoradas ou ainda corrigidas. 
A concepção de que a chama de uma vela encapsulada se apaga porque o oxigênio é totalmente consumido é persistente e compartilhada por professores no ensino de Ciências, porém esse experimento precisa ser empregado, de forma crítica.Nesse sentido, o estágio na modalidade regência possibilita ao estagiário analisar as ferramentas de experiência de atuação da prática pedagógica no processo de ensino e aprendizagem e o ambiente escolar com relevância tanto no aspecto físico como humano.

Este momento de experimentação, embora que simples, despertou a curiosidade e o interesse da maioria dos alunos pelas aulas de Ciências. A montagem e o acompanhamento do experimento foi instigante para eles, pois aprender com a Ciência e ter uma aula dinâmica com poucos recursos, foi surpreendente para os estudantes. Ao longo dos resultados percebeu-se a surpresa e satisfação dos alunos diante da prática, ficando claro com os questionamentos e dúvidas lançadas pelos mesmos durante a aula. Pôde-se notar a partir dessa experiência docente a importância do aspecto da prática para tornar as aulas mais participativas e estimulantes. Ressalta-se, ainda, a necessidade de repensar sobre o currículo escolar de Ciências, e a postura dos professores no que diz respeito à dedicação ao transmitir o conhecimento científico.

O ensino de Ciências no ensino fundamental II sempre requer adequação e seleção de conteúdos, uma vez que as teorias científicas, por sua complexidade e alto nível de abstração, não são passíveis de comunicação direta aos alunos de ensino fundamental (BRASIL, 1998).

Barbosa et al. (2012) informam que o estágio supervisionado tem por intuito- alertar ao futuro professor que deve estar aberto para mudanças e inovações a partir de um redimensionamento de sua ação docente, de sua prática educativa, independente do sistema escolar que esteja inserido, da natureza administrativa que ele trabalha, deve ter o compromisso com a qualidade do ensino e com o seu aluno.

\section{CONCLUSÕES}

Um simples experimento trouxe como resultado um grande aprendizado: não só o professor pode ou deve conduzir as atividades em sala, os alunos tornaram-se construtores e colaboradores das próprias aulas, dessa forma, puderam aprender de uma maneira mais prazerosa e satisfatória. Assim, conclui-se que foi imprescindível a experiência de estágio como uma forma de saber quais os novos rumos e direcionamentos devem ser tomados para a nova geração de professores de Ciências, diante das realidades do nosso país e, sobretudo, do Estado da Bahia.

\section{AGRADECIMENTOS}

Agradeço à administração do Colégio Municipal de Alagoinhas, por ter aceitado a proposta do estágio na escola. À professora regente da turma Daniela Moitinho, pela receptividade. E sobretudo à professora Doutora Magnólia de Queiroz pela orientação e acompanhamento durante o estágio.

\section{REFERÊNCIAS}

BARBOSA, S. C. D. A; REIS, P. C.; MACHADO, D. P. Análise das experiências da disciplina de Estágio Supervisionado do Curso de Letras em Curitiba. In: SEMINÁRIO DE PESQUISA EM EDUCAÇÃO DA REGIÃO SUL, 2012.

BRASIL. Parâmetros Curriculares Nacionais: Ciências Naturais. Brasília: MEC/SEF, 1998.

ROSITO, B. A. O ensino de Ciências e a experimentação. In: Construtivismo e ensino de Ciências: reflexões epistemológicas e metodológicas. 3 ed. Porto Alegre, 2008. 
SOUZA, M. D. A; GONÇALVES, A. E. C. Relato de experiências vivenciadas durante o Estágio Supervisionado no ensino de Ciências em uma escola de Educação Básica em Itapipoca-CE. In: FORUM INTERNACIONAL DE PEDAGOGIA, 4, 2012. Anais... Parnaíba, 2012. Disponível em: <http://www.editorarealize.com.br/revistas/fiped/trabalhos/ 4e0cb6fb5fb446d1c92ede2ed8780188.pdf>. Acesso em: 12 abr. 2015.

VILLANI, A; FREITAS, D. Análise de uma experiência didática na formação de professores. Investigações em Ensino de Ciências, v. 3, n. 2, p. 121-142, 1998 Disponível em: <http://www.if.ufrgs.br/ienci/artigos/Artigo_ID41/v3_n2_a1998.pdf>. Acesso em: 12 abr. 2015. 